P K 6109 J3 1890 MAIN

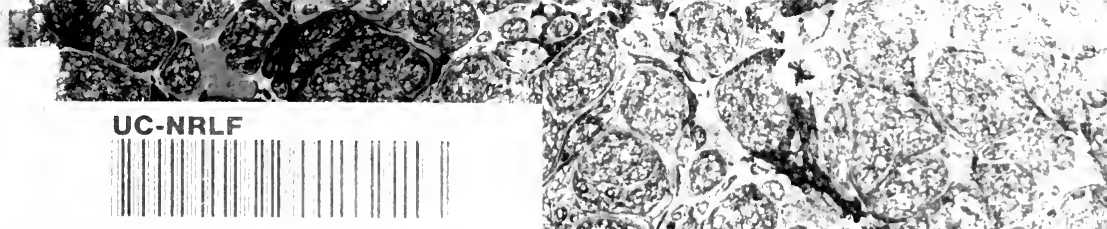

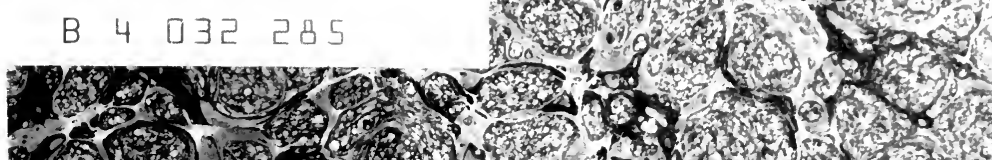

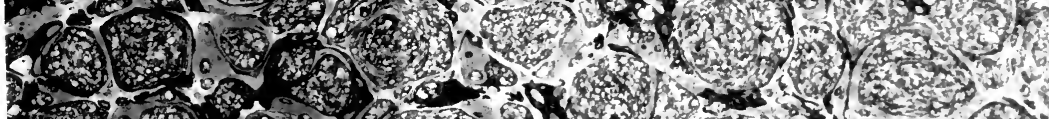

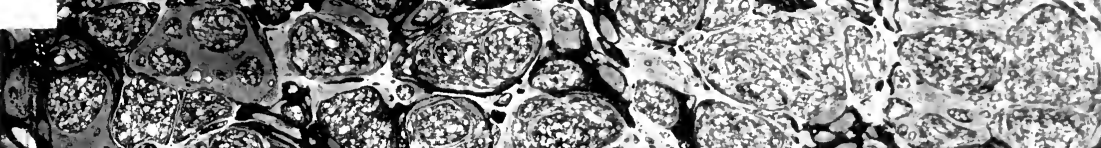

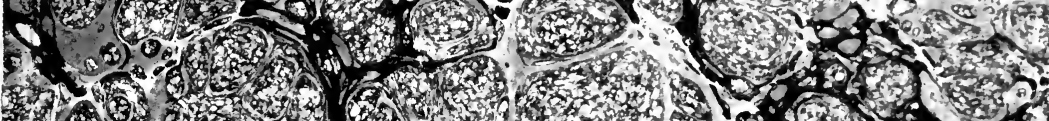

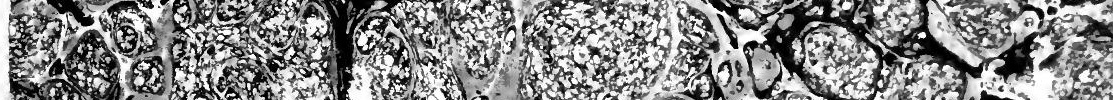

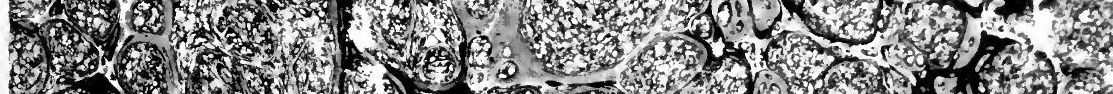
(2)

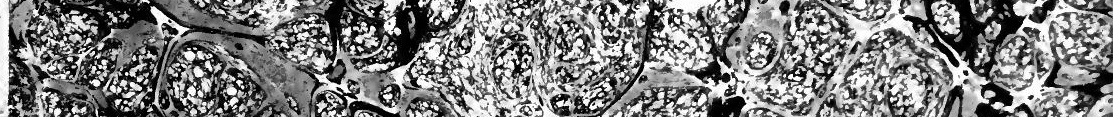
(2) 6.

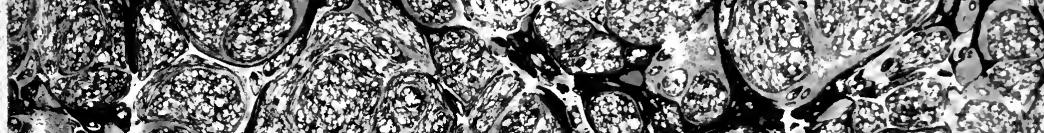

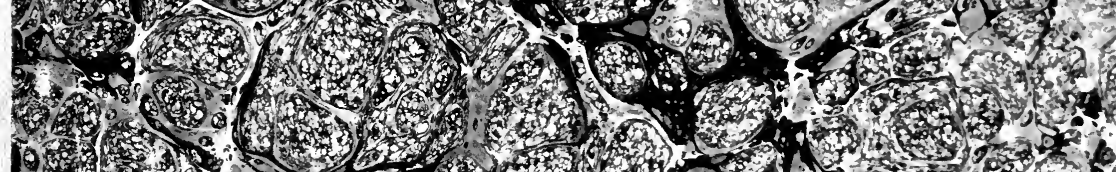
To 20.3.

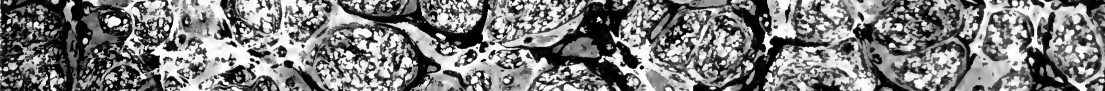

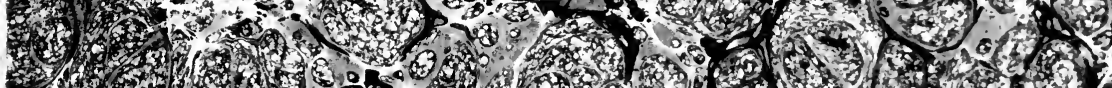

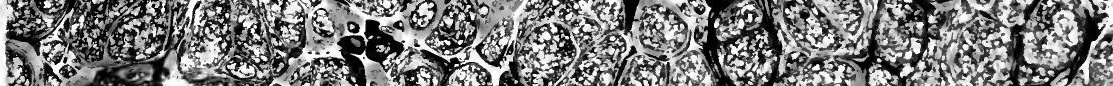

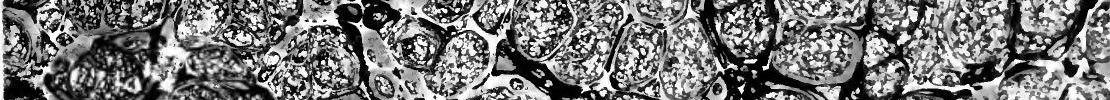

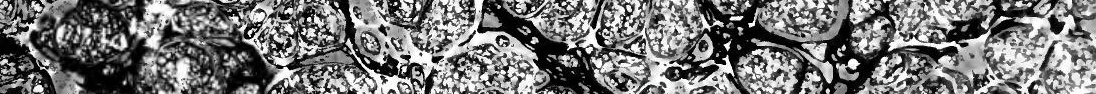

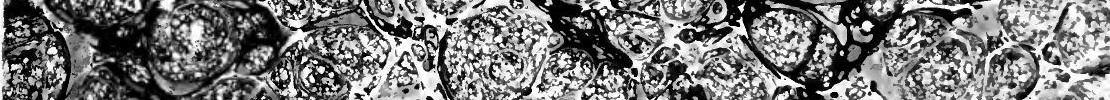

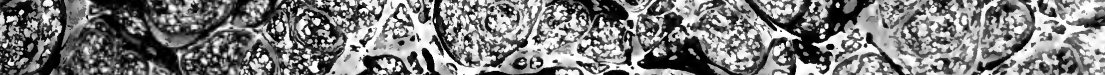

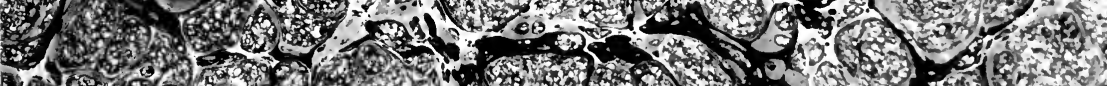

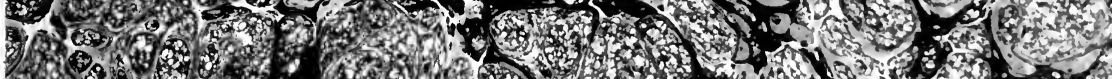

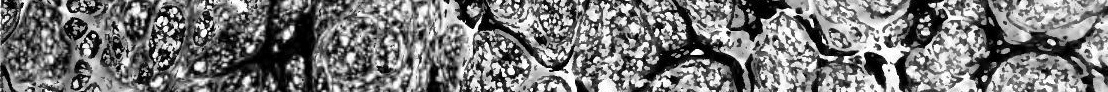

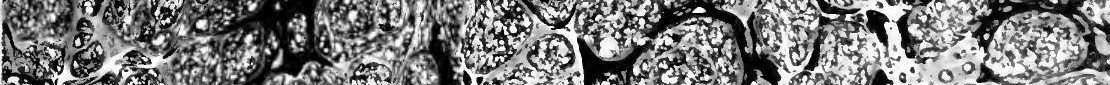

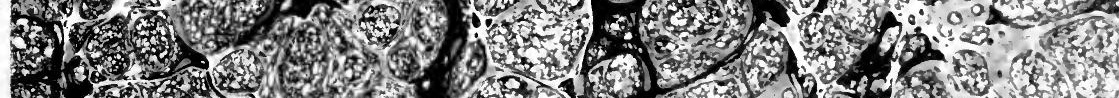
* 5 (1)

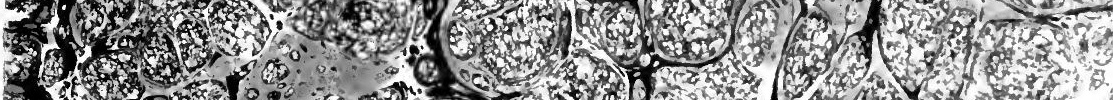

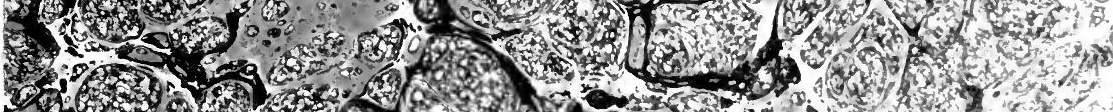

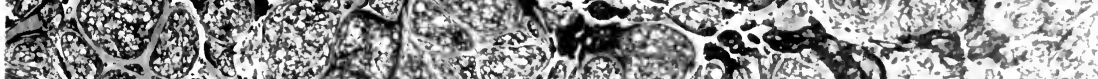

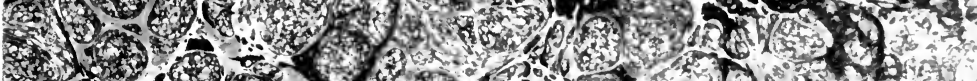

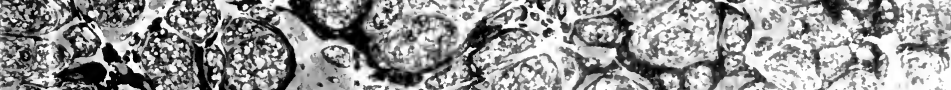


at.

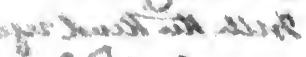

201130
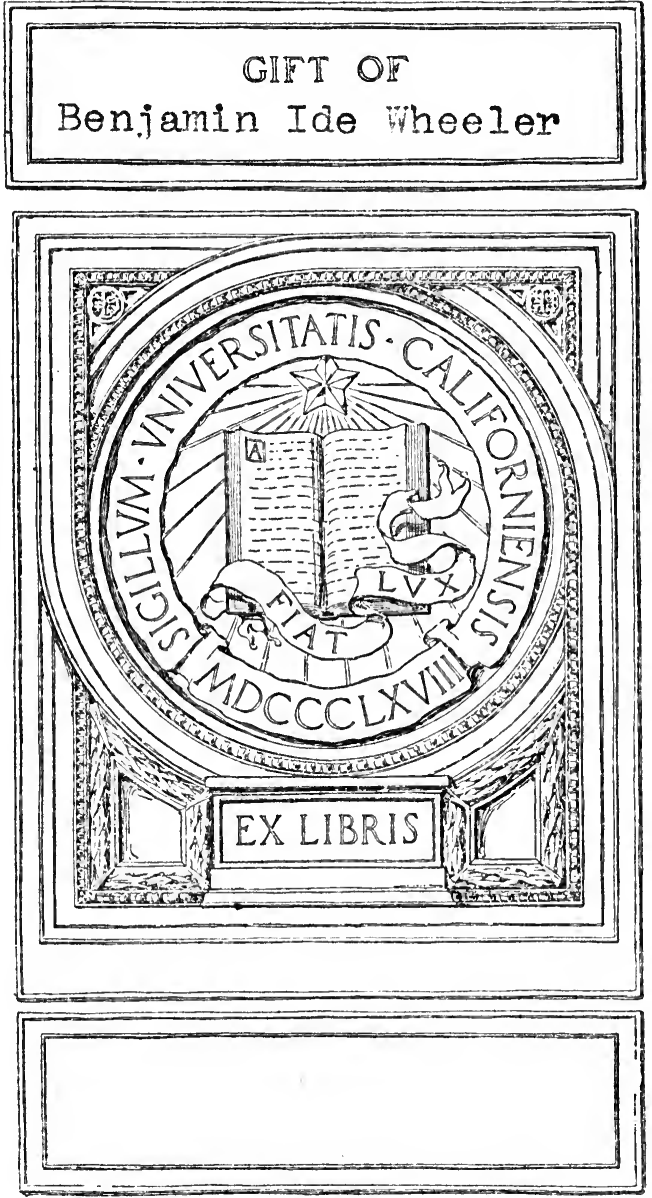


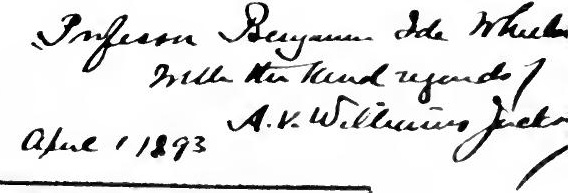

THE

AVESTAN ALPHABET

ANI ITS

TRANSCRIPTION

$\mathrm{BN}$

A. V. Williams JACKSON

of COLUMbia COLLEGE, NEW YORK CITY

WITH APPENHICL

STUTTGART

W. KOH I, IIAMMER 1890 
, 
THE

AVESTAN ALPHABET

ANU ITS

\section{TRANSCRIP'TION}

BY

A. V. WILLIAMS JACKSON

OF COLUMBia COLLEGE, NEW YORK CITY

IVITH APPENIICES

STUTTGART

W. KOIILIIAM MER

i $S_{i j O}$ 
1 


\section{CONTENTS.}

\section{Avestan Alphabet and Transcription.}

The Avestan Alphabet: Its Character............. 5

Lack of Uniformity in Avestan Transliteration . . . . . . . . . 6

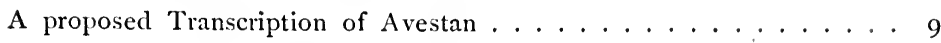

Discussion of the Avestan e-vowels . . . . . . . . . . . . IO

A Modification in Transliteration suggested ........... II

The Ar. Consonants: Germanic Letters as Symbols......... I3

Diacritical Marks on Letters: Discussion . . . . . . . . . I6

Summary of the suggested Transliteration . . . . . . . . 22

\section{Appendices.}

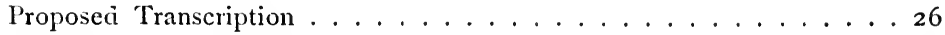

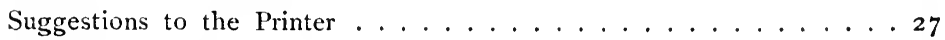

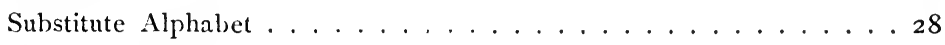

Systems of Transcription . . . . . . . . . . . . . . . 29

Bibliography . . . . . . . . . . . . . . . . . 34 
수 


\section{The Avestan Alphabet \\ and its}

\section{Transcription.}

What the original alphabet was in which the Avesta was written we do not know. The alphabet in which our texts are now preserved bears the stamp of a much later age than the language it presents. The question of the origin of this alphabet in which our MSS. are written has difficulties; but there is little doubt that it is derived from the Pahlavi alphabet of the Sassanian times; it is closely related to the book-Pahlavi. This point must be constantly borne in mind in discussing the letters. The question, moreover, of the transcription of this Avestan alphabet as we now possess it has long been and is still a very vexed one. This is the question, in particular, that forms the chief subject of inquiry in the present paper; but all investigations into the matter of transcription imply a more or less extended study of the alphabet from the standpoint of palaeography, phonetics and philology.

The lack of uniformity in the system of transliterating the Avestan characters is confusing to those pursuing philological studies; it has doubtless also in some degree retarded the advancement of the Avestan cause. From the standpoint of philology, the present necessity of some accordance in the method of transcribing this language is apparent. The time is not far distant, it seems, when scholars should and will tend toward adopting some uni- 
form system. Geldner's new edition of the Avestan texts has practically fixed the number of characters to be transcribed, and should Iranian students now agree-and it is hoped that those in America may perhaps set the example --in adopting some uniform method of transliteration, that shall be practical as well as scientific, an additional impetus would be given to these studies. Such adoption would be a grateful service to all, particularly to those interested in the linguistic importance of the Avesta to Philology. To write on the subject may not be a thankless task; if some suggestion or hint thrown out lead but a step in the right direction as a guide to others for finding a better way, the labor will be quite repaid. To the linguist, moreover, the comparative table of the various systems of transcription, appended for reference (see Appendix), may not be unacceptable.

In regard to the method of Avestan transliterations, the number of systems is almost legion. Many of them, however, differ from one another only in some minor points; in fact, on most of the ordinary details there is a growing tendency more and more toward uniformity. It is chiefly in a certain few respects-but these points are important ones-that Avestan scholars still mainly disagree. Some of these differences have been due to variations in the Avestan characters of some of the MSS. or to different forms adopted in the editions; but since the new edition has set up a standard, the question of the actual Avestan characters to be transcribed has become practically settled, and it seems as if greater agreement might be brought about. Of course those who have to deal with palaeographic questions of the MSS. will be compelled to add other signs in transliterating, but this need not concern philologists generally. By a few mutual concessions, uniformity and concord in rendering the symbols of the Avestan texts might soon result. 
The transcription here offered is presented in a tentative way, in the hope that some of the hints may prove useful for the future. It has been based on personal advice and suggestions upon various points, from names of no less authority-linguistic, palaeographic, philological, and phonetic - than Professors Brugmann, Geldner, Pischel, and Sievers. To these was added weight from the standpoint of epigraphy-Professor Andreas. Practical suggestions have also been received from Professors Delbriick, Collitz, Hopkins, and Lanman. The marshalling of such names is of itself not without significance; the question is one that really is of interest to many scholars. The opinions on the subject of course varied. The transliteration, which I here suggest, is given as a sort of compromise and concession both to the radical and to the conservative side of the question. The system has endeavored to be at the same time strictly scientific and yet as far as possible practical. With a little good will, perhaps out of this system some uniformity of method might be developed and adopted. In America at least we have now the opportunity of uniting; if a few will take the lead, others will follow.

In preparation of this system the various methods of transliteration (Bartholomae, Hübschmann, Justi, de Harlez, Sacred Books, etc.) have been examined: the aim throughout has been to hold the mediam viam.-The $\mathrm{m}$ a in $\mathrm{fe}$ tures of the system are (I) that it shall be scientific and at the same time fairly practical. (2) Single characters as far as possible are represented by single signs. This latter is far more practicable, and at the same time more requisite, in Avestan than it is in Sanskrit. (3) It makes concessions as far as possible to existing systems, and as far as may be avoids radical alterations and introductions. - The particular points characterising the system are: (I) a remodelling in transcription of the 
$e$-vowels;-(2) adoption of the more or less generally used Germanic characters $d, p, \delta, \eta$ for the spirants; similarly also for the nasal, cf. also aspiration;-(3) uniformity in the use of a diacritical sign to differentiate letters. For such a diacritical sign in Avestan, the practical proposal is made to use a subscript tag . (inverted apostrophe, comma, spiritus lenis or the like) to designate the Avestan 'derivation stroke' discussed below p. i6.

In regard to the character of the transliteration as being scientific, it must of course be said that when extensive Avestan printing is to be done some of the transcription types would have to be cast. But in most offices that do philological work, the majority of the types required are already on hand; the few that may not be, can always be mechanically made without much difficulty. In this way the practical side of the question has been kept in view. In smaller articles the transcription can always be used without the necessity of having the type cast; the signs in general are such as can be made up by any intelligent compositor. ${ }^{1}$ In this respect the more consistent use of the modifying 'tag' ( $\left.\iota_{\iota}\right)$ is very practical. The tag, moreover, when cast on the letter breaks off less easily than the point. For purely popular articles Justi's transliteration somewhat remodelled may of course be retained - see Appendix 'Substitute Alphabet'.

The Av. transcription tentatively proposed is now given. The order of letters is based on that of the Sanskrit alphabet. For convenience of reference, moreover, Justi's transliteration, Handbuch der Zendsprache, is given beneath each letter. The letters in parenthesis () show where deviations from Justi have been made.

1 Reference, for example, might here be made to several Notes by the writer in the American fournal of Philology 1889-90 where the system was thus employed. 


\section{Proposed Transcription of Avestan. ${ }^{1}$}

(Compared with Justi, Mandbuch der Zendsprache).

\section{A. Vowels.}

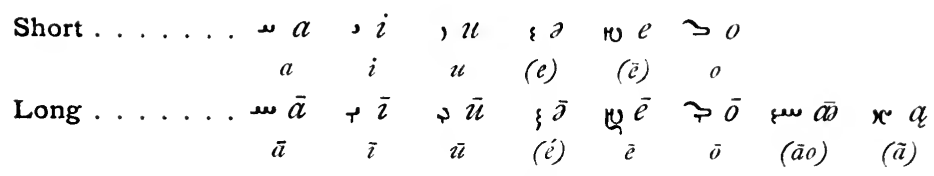

B. Consonants.

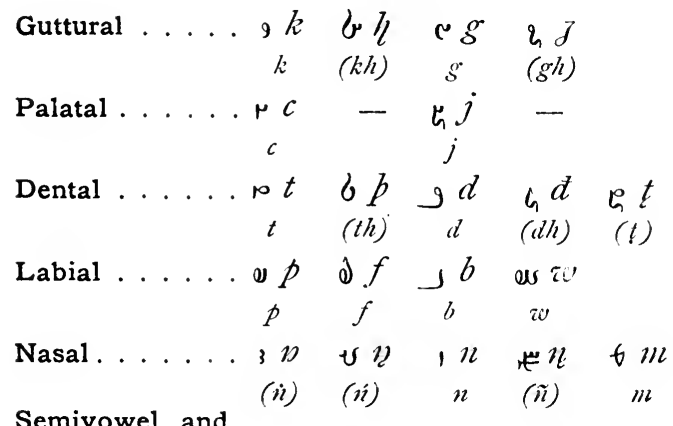

Semivowel and

Liquid.... . w (s) y (i) $)^{2} \quad$ Ir

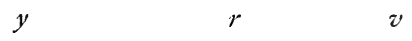

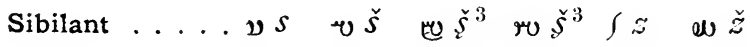

(f) (s) (sh) (sk) $\cdots$ (zh)

Aspiration .... $e^{h}, \omega$

$h \quad(q)$

Ligature . . . . $\mu h^{*}$

(q)

In the above alphabet a certain number of the Avestan characters are simple and have in general corresponding Latin letters that may represent them. All unite now in transcribing these in the ordinary manner. They are-

${ }^{1}$ For a merely practical transliteration to be used for popular purposes, see 'Substitute Alphabet' p. 28 below.

2 The signs $i, \not$ need be employed only for purely scientific purposes; the letters $y$, $v$ for both initial and internal ro $", \downarrow)$, answer fully for practical purposes.

${ }^{3}$ The single sign $\check{s}$ is quite sufficient for the three $v$, ש, r. The differentiation $\check{S}, \breve{s}, \breve{s}$ need only be made in scientific articles. 


$$
\begin{aligned}
& a, \bar{a}, i, \bar{\imath}, u, \bar{u}, o, \bar{o} \\
& k, g, t, d, p, f, b \\
& n, \quad m \\
& r \\
& s, z, h .
\end{aligned}
$$

In regard to the others, questions of greater or less importance arise and there is more or less diversity in respect to them. Beginning with the vowels these may now be taken up in detail.

A. VOWELS.

A Modification in Transcription of the Vowels.

$$
\begin{gathered}
\text { Av. } \varepsilon, \xi-v, w-\varepsilon w ; x . \\
\text { ə, } \bar{s}-e, \bar{e}-\bar{a} ; \alpha . \\
e-\mathrm{V} \text { owels. }
\end{gathered}
$$

r. Av. \& $\Rightarrow$ (Justi $e$ ).

Av. . s s

The fact that Av. s is not a pure $e$-vowel has long been recognized. There have consequently been various different methods of denoting it, e.g. $e$ or $\ddot{a}$ (Rask, Ueber $d$. Alter $u$. Echtheit der Zend-Sprache), $\breve{e}$ (Spiegel, Av-Uebersetz. etc.; Geiger, Handbuch der Aw'estasprache), e (Fr. Müller, Wiener Zeitschrift), etc. A critical study of this letter shows that it must have represented an obscure sound that seems closely to have resembled the short indefinite vowel familiar in English, 'gardener', 'history', 'potato', 'measuring', 'mutton', 'against', 'forward', 'sachem', 'form $i$ dable'. It seems to have approached sometimes more nearly to $a(i)$, sometimes to $u(\bar{o}) .{ }^{1}$ A study of the MS. variants in this respect is very instructive.

The $a$-tendency of $;$ is seen, for example, in endings e.g. Av. taysure yasnam, ny baran= Skt. yajuám, ábharan.

${ }^{1}$ Cf. e.g. Ys. 57.2 variants pivōrastō, pwarastō, pwarasatō, pwarasatō, etc. Cf. also $\xi \bar{\jmath}$ below, GAv. $n \bar{\delta}=$ YAv. $n \bar{o}$ etc. 
So GAv. avisti $=$ Skt. avitti $^{1}$ Again, observe the interchange between $ə$ and $a$ in the MSS., e. g. upamam beside up-a-mam, mainyavim beside mainy-a-vō etc. Furthermore, the $a$ that arises from $a$ before $m$ or $n$ may be palatalized to $i$ when either $y, c, j$, or $z$ immediately precedes. The variants show the palatal nature of the sound e.g. Av.

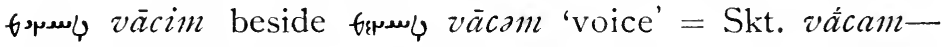
cf. Jackson, Avesta Gram. \$§ 29, 30. Independent variants between $\partial$ and $i$ occur quite often, even when no palatal precedes, e. g. namata-, nimata- Vd. 5.38, bisangra-, bəzangra- Ys. 9.I 8 and many others.

The $u$-nature beside its $i$-shading is also noticeable. In GAv., for example, a appears sometimes to be written (as a kind of dissimilation) for $u$ or $i$, when in the following syllable an $u(v)$ or an $i$ stands; the epenthetic vowel may then be also written beside it. This proves the labial character in addition to its palatal. Thus, GAv. -p pupely dragvant- 'wicked' (= *drugvant- to Av. druj-); GAv. bosvant- 'advantageous' (= *busvant- to Skt. bhuj-); GAv. ušzuru- 'zeal' (?) Ys. 34.7, cf. uš-u-ruyē Ys. 32.I6; GAv. hušs $\partial^{i t i-}$ 'well-being' (i. e. huš-i-ti-); GAv. jnziti- Ys. 3o.II; GAv. àskaiti- Ys. 44.17. See Av. Gram. § $3 \mathrm{I}$.

Such interchanges with $a, i, u(\bar{o})$ are indicative of the intermediate character of the sound. ${ }^{2}$ For all these reasons, it is here suggested to adopt the transcription (3) commonly used in Phonetics (cf. Sweet's Hist. of Eng. Sounds 2 ed. p. I 5 etc.) for the sound that seems so closely to resemble it. This choice of the 'turned $e^{\prime}$ (a) is a practical one; no new type need be cast. The compositor has simply to reverse the $e$ (ग).

1 Cf. Eng. avowal, pron. avowal.

2 Palaeographically Av. $\xi$ is connected with Pahlavi $\mid u$, i. e. merely a broken 1 (i). For some excellent points bearing on the Pahlavi and the Inscriptions in regard to this letter, I am personally indebted to the courtesy of Professor F. C. Andreas. 
2. Av. $\xi \bar{\partial}$ (Justi $\left.e^{\prime}\right)$.

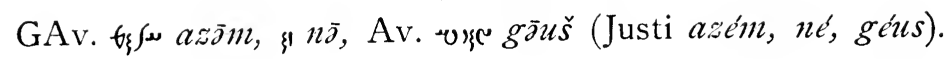
The sound $\xi \bar{\partial}$ is the corresponding long to $\xi \partial$ and is therefore to be represented (j) in accordance. It is found chiefly in GAv. ${ }^{1}$ answering to YAv. $^{1} \partial, a, \bar{o}, q .{ }^{2}$

$$
\text { 3. Av. we, } e_{\tilde{e}} \overline{\text { (Justi }} \bar{e} \text { ). }
$$

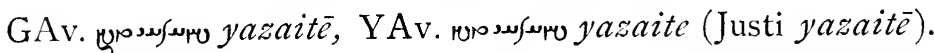

These two, w $\omega$, correspond to each other in the MSS., as short and long. They are therefore to be distinguished. Justi etc. in accordance with the first editions gave both as $\bar{e}$. Later it became customary, as was proper, to distinguish them from one another and a subscript point (thus $e \bar{e}$ ) was used to differentiate them from $e \bar{e}$ which were adopted for $\varepsilon \xi$. This now is no longer necessary;

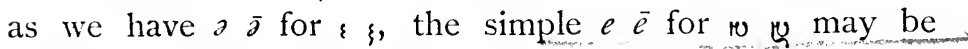
adopted. That brings them in direct accord with their parallels $>0,>\bar{o}^{3}$

\section{Av. мu $\overrightarrow{a s}$ (Justi $\ddot{a} o$ ).

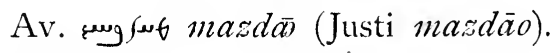

Palaeographically, wis evidently a combination of

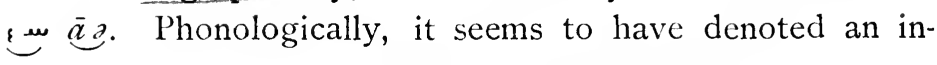

${ }^{1} \mathrm{GAv}$. = Găthā Avesta, all that is written in the Gāthā dialect.YAv. = Younger Avesta.

2 l'honetically $\xi \bar{\partial}$ probably resembled the long drawn English pronunciation of 'word' (wəord i. e. ör), 'earth' (əərth i. e. er), 'turf' (təarf i. e. ur), 'first' (farrst i. e. ir) etc., ef. Sweet, Hist. of Eng. Sounds p. 276.

${ }^{3}$ If $\supset>$ are universally' rendered $o \bar{o}$, consistency requires that $\mathrm{T} \in$ should likewise be given without the subscript point. Perhaps both sets, however, would orthographically better be given by some diacritical mark e. g. $\varrho, \bar{o}, e, \bar{e}$ (though (.) generally denotes a lingual letter). They are not pure sounds. This is shown, for example, by vohu, cōrot, yesne, and such MSS. interchanges $e, a, i$ etc. It must be remembered that Av. $\bar{o}, \bar{e}$ $=$ Skt. $\bar{o}, \bar{e}$ only when final. Ordinarily Skt. $\bar{o}, \bar{e}$ are represented in Av. by $a o, a \bar{e}$. A fuller discussion must be reserved for some future time. 
definite 2 -shading of $\boldsymbol{w} \bar{\alpha}$. It fluctuates in the MSS. on the one hand with mazdāo; on the other hand it is found as a variant for

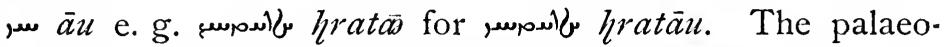
graphic and phonetic character of the letter, then, are thus given

$$
\text { w }(\xi)=\bar{\alpha}(\bar{a} \partial) \text {. }
$$

In printing, $\overline{a s}$ if not provided, may be mechanically made by uniting $a \partial$ under the macron $\overline{a \partial}$.

$$
\text { 5. Av. } x \underset{\imath}{\underset{\imath}{a}(J u s t i} \tilde{a}) \text {. }
$$

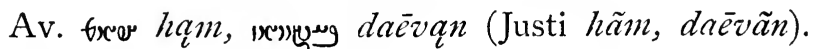

The letter $x$ presents a nasalization of $a, \bar{\alpha}$; sometimes it also resembles Skt. anusvāra. To render it, the character $a$ has been preferred to $\tilde{a}$. The symbol $a$ is now more generally used in linguistic works to represent the $a$-sound with nasal coloring. It is preferable in case the question of accenting the vowel (') ever comes up. Of course in popular works $\hat{a}$ may be retained. The symbol a may be mechanically made by placing a subscript hook 。 below the letter. ${ }^{1}$

\section{B. CONSONANTS.}

a. Germanic Letters as Symbols.

$$
\text { Spirants. }
$$

$$
\begin{array}{r}
\text { Av. } b, \quad 2, \quad 6, \quad 4 . \\
\eta, \quad, \quad b, d .
\end{array}
$$

All scientific work in Avestan implies extensive comparison with Sanskrit; on this account the Av. translitera-

1 Strictly the L should be varied somewhat from the 'tag' below referred to, in order to show that it represents a somewhat different modification. 
tion is always to be brought into closest symmetry with the Skt. transcription. This is practical and it is necessary. It is necessary, however, on the other hand to avoid confusion with the Sanskrit. Confusion sometimes arises from using a symbol in Av. with a different value from that which it familiarly has in Skt., or the same sign for sounds that differ enough in Skt. and Av. to require a distinction to be made between them. A striking point, for instance, in which differentiation between the two may be made is in the matter of the Av. spirants. The possession of spirants as contrasted with the Skt. aspirates is one of the characteristic phonetic features of Avestan. For scientific purposes, then, these Av. spirants should be distinguished from the Skt. $k h, g h, t h, d h$. Nor is this to be done alone of account of the difference of sound-the symbol having a spirant value in transcribing the one language and an aspirate value in transliterating the other - -but also, it might be added, because confusion in Av. may sometimes thus arise from the fact that $g h$ in this way should have to stand for the single character $q(7)$ and for the double letters ere $(g h)$ found in $\mathrm{G}(\mathrm{Y}) \mathrm{Av}$., e. $g$. GAv.

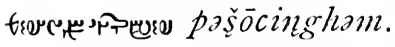

To obviate this possibility of confusion, recourse has been had on the one hand to the Gk. characters $\%, \theta, \delta(\beta)$ by some (especially Hübschmann, Umschreibung der iran. Sprachen; cf. also K.Z. xxiv. p. 323), on the other hand to letters derived from Tuetonic signs $\eta, j, b, d$ (Rask, Westergaard; esp. Pischel, Bartholomae). The general tendency (e. g. cf. Brugmann, Grundriss; etc.) seems now to accept the Germanic rather than the Greek signs; they are therefore here adopted. Comparisons with Greek words, moreover, are more common than with Germanic; less confusion therefore thus results and such un-Avestan looking words as yafos are likewise avoided. In America, Eng- 
land, and Germany the A. S. $p, d, j$ if not actually on hand are always easy to obtain whenever scientific transcription is needed; and $\zeta$ can be supplied by an Old English or German long $h(\mathfrak{h})$. Almost all philological typefonts contain the former two, at any rate, of these signs. They possibly are open to some objection from the Romance side; but the substitutions offered under each should be considered. These spirants may now be taken up in detail.

\section{Av. \&り (Justi kh).}

Av. ugsaulb hratōuš (Justi klıratéus).

Palaeographically the Av. character $b(k h)$ is derived by the upward 'derivation stroke' from the Pahlavi $2 h$. A good transliteration \ was suggested for it by Pischel (B.B. vi. p. 275). The character $\zeta$ is somewhat similarly derived from the long Gothic $h$. It may always be given by setting an ordinary Old English or German long $h(\mathfrak{h})$.

\section{Av.,$\delta$ (Justi gh). \\ Av. bily, uzram (Justi ughrem).}

For the spirant $q$ the symbol $z$-the ordinary roughened $g$. of the Anglo-Saxon-is used, as often. It is on hand generally in philological type-fonts. If not, it can possibly be given by the long $z$ of $0 \overline{3}$, or better the compositor may set a simple Old English or German $g(\mathfrak{g} \mathfrak{g} \mathfrak{g})$.

\section{Av. $6 p$ (Justi th).}

Av.

The dental spirant $\zeta$ is derived from the Av. sign for $t$ by the upward derivation stroke. It is represented, as often, by the common A. S. 'thorn'; this is certainly found in all type-fonts that do linguistic work. 


$$
\begin{aligned}
& \text { 9. Av. } \left.\iota^{d} \text { (Justi } d h\right){ }^{1} \\
& \text { Av. } \left.{ }^{1} \zeta^{\circ} i d a \text { (Justi } i d h a\right) .
\end{aligned}
$$

The symbol $d$ or $\delta \dot{\delta}$ is the common A. S. 'edh' or crossed $d .^{2}$

\section{b. Diacritical Marks on Letters.}

In transcribing Oriental alphabets there are always a certain number of characters that may be well represented by merely adding to similar Roman letters a diacritical sign as mark of differentiation. It is proper that the diacritical mark should be used consistently throughout. Furthermore, since comparisons between Avestan and Sanskrit must constantly be made, it is necessary again to avoid using a diacritically marked letter with a special value in Sanskrit and then employing the same marked letter is a slightly different function in Avestan. Confusion arises from disregard of this point. Thus, Justi's $t(l)$ is confusing as it represents a different sound in Av. from that which $t$ (cerebral, lingual) familiarly has in Sanskrit. Again, $h$ for Av. $\leftleftarrows$ would be confusing on account of Skt. visarga. ${ }^{3}$

A palaeographic study of the MSS. shows that many of the Avestan characters are actually derived from one another or differentiated by a stroke $l_{\zeta} s$ or curve which Professor Geldner orally termed a 'derivation stroke'.4

${ }^{1}$ For the voiced labial spirant er (Justi $w$ )-derived from $\boldsymbol{e}$ by the derivation stroke-the simple letter $w$ with the German pronunciation, has been retained as is generally done. A crossed $b$ i. e. $b$ which is used by some scholars in Gothic transcription, would perhaps well represent it orthographically, but here strict conservativism seems preferable.

2 On $3 x, y \geq, \mu$ see below.

${ }^{3}$ Scientifically, however, visarga in Skt. seems better transliterated by $\underline{h}$ or the like, the subscript point (.) being reserved for the linguals t, th, $d$, , $l h, n$.

${ }^{4}$ For many interesting particulars connected with the MSS. in this respect especially, and for valuable hints I am deeply indebted to the kindness of l'rof. K. F. Geldner. 


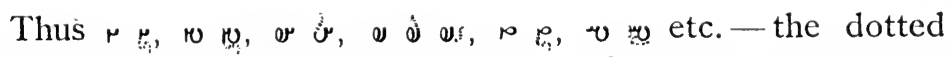
line denoting 'derivation stroke'. '. Systematic treatment suggests that we should adopt some similar method to differentiate the Latin letters whenever it is necessary to designate such modification in transcribing Avestan characters. At the excellent suggestion of Dr. Geldner, a 'tag' $\left({ }_{\iota}\right)$ has been adopted to be used somewhat in conformity with the 'derivation stroke' whenever it is necessary and possible thus to differentiate. Practical grounds favor such adoption: when the types are cast the 'tag' breaks off less easily; furthermore, it may always be mechanically constructed by an inverted spiritus lenis ( ) set close or even by the turned apostrophe (.). The plan, therefore, is thoroughly practical; the tag will also serve somewhat in recalling the palaeographic character of the letter it is used to designate. ${ }^{2}$ To prove that the tag as modification can be readily employed, reference may be made to some Avesta Notes by the present writer in the American Fournal of Philology I $889-90$.

The letters diacritically marked by the 'tag' either as sign of differentiation or as a representative of the Av. 'derivation stroke' may now be taken up in detail.

$$
\begin{gathered}
\text { го. Av. } e t \text { (Justi } t \text { ). } \\
\text { Av. y yarat (Justi barat). }
\end{gathered}
$$

The Av. letter $e$ is one whose phonetic nature is uncertain. Justi employed $t$ to transcribe it. This is open to objection; the subscript point (.) brings in confusion with the Skt. lingual $t$. Various other devices have been used to represent it-see Appendix p. 3I. Whatever the

${ }^{1}$ See also Rask, Echtheit p. 57, 50, 'Zug', 'Aspirationszug'; Spiegel, Gram. p. 17 'durch Anfügung eines Striches'; Hübschmann, K:Z. xxiv. p. 339 etc.

2 A 'tag' as modification sign is elsewhere in use, cf., for instance, Sweet's Anglo-Saxon Reader; Sievers-Cook's Grammar of Old English, et al. 
phonetic value of the letter may have been, its palaeographic character is clear; $\varphi$ is formed by the 'derivation stroke' ${ }_{4}$ directly from o $t$. It may therefore be consistently represented by $t+_{6}$, thus:

$$
e(p+c)=t(t+c) \text {. }
$$

Observe that $t$ is mechanically to be made as before by means of the inverted comma shaved off and set close, or by the turned apostrophe.

$$
\begin{aligned}
& \text { Nasals. } \\
& \text { Av. 3, v, 1, 世. } \\
& n, n, n, n \text {. } \\
& \text { I I. Av. } 3 n \text { (Justi } \dot{n}) \text {. } \\
& \text { Av. evers anhat (Justi anhat). }
\end{aligned}
$$

For the guttural nasal 3 (Justi $\dot{n}$ ) the symbol $n$ derived from the old long tailed Germanic $n$ has been adopted. This is the common designation for the guttural nasal in linguistic works. ${ }^{1}$ In short articles where scientific transliteration is required, the symbol $n$ may be produced mechanically by inverting $a(x)$ and opening the bottom with a penknife, thus $\boldsymbol{n}$.

\section{Av. y $y$ (Justi $\mathfrak{n})$.}

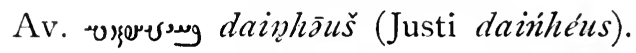

The character $y$ is palaeographically a modification of 3 ; it occurs for $3 n$ in connection with $h$ when preceded by an $i$ - or $e$-sound. The two $3 v$ interchange often enough in MS. variants to show the resemblance that $y$ must have had to 3 in form and in force. The palaeographic cha-

1 The sign $\dot{n}$ (Justi) should be reserved for the Skt. palatal $\dot{n}$ (Whitney $\tilde{n}$ )-see the suggestion by Pischel, Gött. gel. Anz., 14. Juni 1882, p. 738 seq. The letter $N$ is preferable also for the guttural nasal in skt. (Whitney $\bar{n}$ ) when comparisons with Av, are made. 
racter of $y$, the transcription consistently recognizes by attaching the modification tag $\left(_{\ell}\right)$ to $n$, thus forming $v^{1}$

$$
\begin{gathered}
\text { г3. Av. } n \text { (Justi } \tilde{n}) \text {. } \\
\text { Av. yaranti (Justi bareñti). }
\end{gathered}
$$

Palaeographically ing an $a$-sound with $n$. In appearance it resembles $x a$ of the MSS. .In usage, however, is merely a modification of , $\dot{n}$ before stopped consonants. According to the system, therefore, it will be represented by $n$ with the modification tag. This tagged $n$ (n) recalls on the one hand the true $n$-character of $\ldots$; on the other its external resemblance to the nasalized $x a$.

Sibilants.

$$
\begin{aligned}
& \text { Av. ע, } 0, \text {, } 2, r-\omega \text {. } \\
& s, \quad \check{s}, \quad \check{s}, \quad \check{s}-\check{z} \text {. }
\end{aligned}
$$

14. Av. ข $s$ (Justi $\varsigma$ ).

Av. מעק asti, aspō (Justi açti, acpō).

The letter $y$ shares the nature both of the palatal and of the dental sibilant. It is now universally given by $s$; this is therefore adopted. ${ }^{2}$

$$
\text { I5. Av. v (ש, ro) } \check{s}(\check{s}, \check{s}) \text {, Justi } s(s h, s k) \text {. }
$$

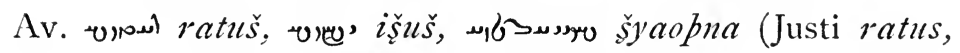
ishus, skyaothna).

From a palaeographic standpoint it is evident at a glance that $y$ forms the basis of the three sh-sounds. The sign $\check{s}$ must therefore likewise form the basis of the three transliterations. It is customary thus to transcribe $\vartheta$ by $\check{s}$ rather than by $s$, in order to avoid confusion with the Skt.

'Justi's $n$ is open to the objection that scientifically the acute (') should be reserved for designating accent.

- 2 For the palatal $-s$ in Skt. (Whitney $s$ ) it seems preferable to use $s$ when comparisons between $A v$. and Skt. are to be made. 
lingual $s$ noted above. Justi's $s$ for w has had of course to be abandoned. Now since $\omega$ is a composite character made by the derivation stroke, it may be consistently rendered by use of the modification tag, thus

$$
\omega(\iota+-v)=\check{s}(c+\check{s}) \text {. }
$$

In like manner ro is palaeographically a modification of $v$ before $y$. This differentiation by means of the, turned in the other direction may be indicated by the reversed tag $\breve{s}$.

The threefold differentiation of $\check{s}, \check{s}, \check{s}$ is not necessary except in transcribing a text for scientific purposes where it is desired to reproduce the differences of the original. For practical purposes, the sharp distinction may be quite disregarded; $\omega$ is final (except before $t, c$ ), 必 initial and internal, ro only before ". The simple $s$ will therefore practically suffice i. e.

$$
\left.\begin{array}{cc}
0 & \check{s} \\
\text { e } & \check{s} \\
\text { r } & \check{s}
\end{array}\right\} \text { or all simply } \check{s} \text {. }
$$

The sign $r$ is on hand in all linguistic type-fonts. The differentiation if found necessary, may of course easily be made as before by means of the subscript tag. ${ }^{1}$ This concludes the sibilants. ${ }^{2}$

\section{Aspiration.}

$$
\begin{aligned}
& \text { Av. } \\
& h, h, h \text {. }
\end{aligned}
$$

The fundamental aspirate is $r h$ (Justi $h$ ). It is a modification of the Pahlavi $\sim h$. In the transliteration of it, all are agreed. In regard to the other two $\omega \mu$ there is a diversity in treatment. Justi wrote both as $q$; but they

1 The ligature rer $\check{s} t$, ror $\check{s}$ c require no further special designation.

2 The voiced spirant sibilant 2 (Justi $z h$ ) is commonly rendered $z$ in conformity with $\check{s}$. No remark is needed. 
are sharply to be distinguished. They will be examined in detail.

$$
\text { 16. Av. } \boldsymbol{h}_{\text {h }} \text { (Justi q). }
$$

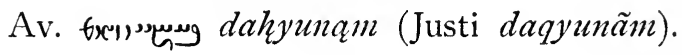

The character $\omega$ is a mere modification of $h$ (Pahlavi $\nu$ ) before a $y$. It may be thus represented:

$$
\omega(h+\omega)=h(c+h) \text {. }
$$

The $h$-sign (Pahlavi $\mu$ ) is the basis; the 'derivation stroke' is represented by the 'tag'.

$$
\begin{gathered}
\text { I7. Av. } w \text { (Justi q). } \\
\text { Av. س } w a \text { - (Justi qa-). }
\end{gathered}
$$

The letter $\mu$ is a ligature of Pahlavi $\nu h$ and,$v$. It interchanges at times with ne hv. To transcribe this ligature, the suggestion is here made that we may aptly use $h$, in itself a similar ligature, that is often used in Gothic transliteration, e. g. Braune's Goth. Gram. transl. by Balg, I 883, cf. $\S 63$. Thus :

$$
\mu(1+)=h(h v) .
$$

As this sign is not always on hand, its place may be supplied by $h$ with a slightly raised $v$, thus $h v$.

Semivowels.

Av. ro (") $y$ (Justi $y$ ),

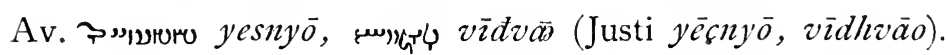

The characters ro $\iota$, as is familiarly known, occur when initial; the forms " " are found when internal. The simple transcription $y, v$ for both the initial and the internal forms has been retained on conservative grounds. The same are retained likewise by Brugmann, Grundriss der indogerm. Sprachen. Confusion can hardly arise; the exceptions to 
the law of the initial-internal forms need scarcely be noticed. Scientifically, however, it is more accurate to adopt $i$ " for " " as has been done by others. Thus:

$$
\begin{array}{ll|l}
\text { ro } & y & \text { or both simply } y . \\
" & i & \text { or both simply } v . \\
\varphi & v & \text { or both } \\
" & u & \text { or bot }
\end{array}
$$

Palatals.

$$
\text { Av. r c (Justi } c \text { ), } h_{j} j \text { (Justi } j \text { ). }
$$

Av. tills cipram, sosugh jasaiti (Justi cithrem, jaçaiti).

The voiced palatal $\xi_{h}$ is palacographically a derivative from $r$. In transcribing $r \xi$ it seems best to be conservative; Justi's $c, j$ are retained; they are likewise kept by Brugmann, Grundriss. The same is almost universally the case in transcribing Sanskrit. Those who wish to be more scientific in this respect are welcome of course to the palatal point over $k, g$, thus $\dot{k}, \dot{g}$.

\section{Ré s umé.}

Such in the main are the characteristics, palaeographic and phonetic, of the letters in the Avestan alphabet upon which there is most discussion; such likewise is the system of transliteration proposed. I have adopted it for my Avesta Series: i. Grammar, ii. Texts, shortly to appear. Many of the points in regard to the alphabet are, to be sure, more or less familiar; in such cases the transcription adopted has merely followed what it seems the general tendency to adopt. May these points become more and more universally agreed upon! The new points in the transliteration are suggestions toward uniformity or toward improvement by remodelling. On the latter, compare for instance the discussion of the $\varepsilon$-vowels. 
The principal features of the transcription suggested may now, therefore, be recalled. They are the consistent use of the 'tag' as a diacritical mark, instead of points or accents. This 'tag', let it be remembered, answers in general to the 'derivation stroke' by which palaeographically so many of the Av. characters are formed or modified. Furthermore, the system marks clearly the orthographic distinction of the three sibilants $\check{s}, \check{s}, \check{s}$, when necessary, also of the nasals $n, n, n, n$, and of the a spirate $h, h, h$. A practical transcription of the much-discussed $\varphi t$ (Justi $t$ ) is suggested. An innovation is made by remodelling the $e \cdot$ vowels, using $\partial, \bar{\jmath}$ as an apt representation of the uncertain $\xi \xi$, and thus bringing w $e$ $u \bar{e},>o>\bar{o}$ into closer relationship - however the latter be rendered. With reference to $r c, \xi j$, es $w^{\prime}, r, \cdots y, \zeta \geqslant v$, conservativism has been used. The Germanic characters $p, d$, etc. have been adopted for the spirants according to what seems to be the apparent tendency of the present.

In conclusion I would like once more to renew my cordial thanks to each of the scholars mentioned at the beginning of the paper. Their courtesy, their suggestions and their advice are cordially appreciated. To Professor Geldner, as always, is my gratitude due for the interest that he personally took in discussing the various sides of the question of Avestan sounds and of their transcription, as well as for the trouble he went to, not alone in giving me valuable points in regard to palaeography, but also for making accurate copies of many letters and styles of MS. writing. To these obligations may be added my indebtedness to the publisher, Herrn W. Kohlhammer, and to the compositor, Herrn Säuberlich, for the form and for the accuracy with which the paper is presented.

It remains alone to repeat the hope that Avestan scholars may strive more toward union in transliteration. 
The above system represents in most points what seems to be the general drift in regard to scientific transcription of the Avesta; it has only added or modified where alterations seemed necessary; and the practical side of the question, withal, has been kept as much as possible in view. If its main points should receive the sanction only of certain scholars, how many there would be would follow these!

A. V. Williams Jackson

July 1890.

Columbia College

New York City. 
Appendices. 


\section{Appendix I.}

\section{Proposed Transcription of Avestan.}

(Compared with Justi, Handbuch der Zendsprache). ${ }^{1}$

A. Vowels.

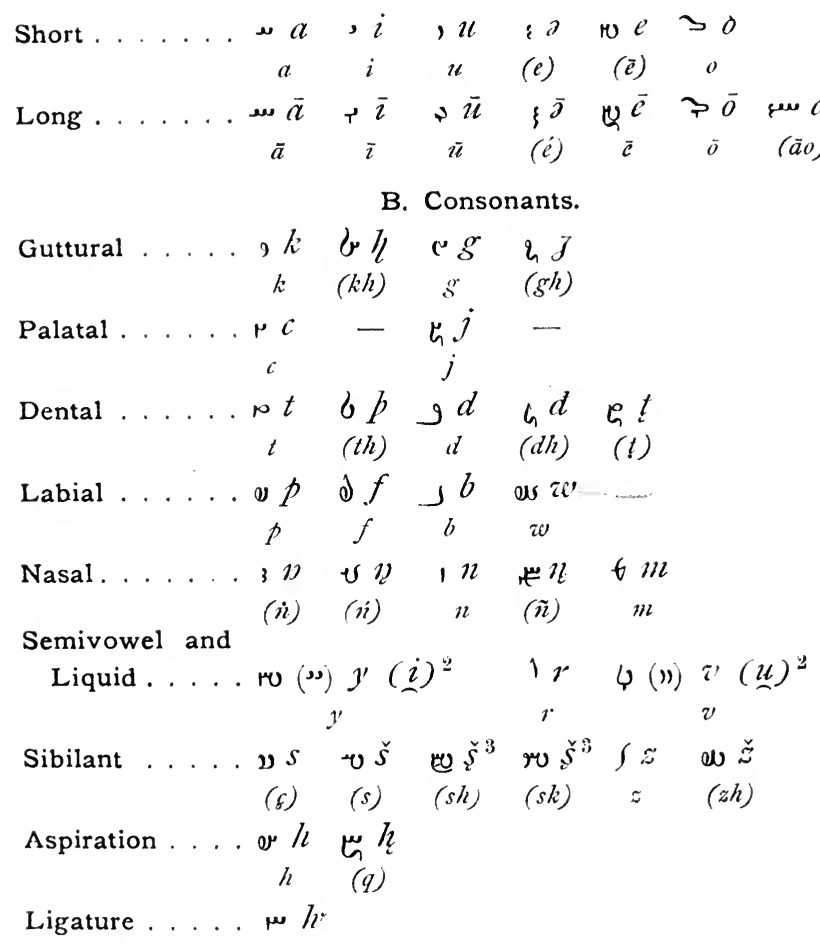

(q)

1 Forms in parentheses () show where Justi has been deviated from.

2 The signs $i, k$ need only be employed for purely scientific purposes; the letters $y$, $v$ for both initial and internal $r$ ", $\lfloor "$ ", answer fully for practical purposes.

3 The differentiation $\check{s}, \breve{s}$ need only be made in scientific articals. The single sign $\check{s}$ is ordinarily quite sufficient for the three $v$, שe, r. 


\section{Appendix II.}

Suggestions to the Printer.

For small articles when special types not cast.

(See Alphabet, Appendix I.)

Vowels $\partial, \bar{y}, \bar{a}$.

The $a$ is simply a 'turned' $e:-j$, turned $a$ with macron $\left(^{-}\right)$as quantity mark.-For $\bar{b}$, set $\bar{\alpha} a$ close together by shaving edge of type a little; then unite under macron.

Unusual Signs $l, j, p, d, n, h$.

For $\eta, j$, set Old English or German or similar long $h, g .-p, d$ are Anglo-Saxon 'thorn', 'edh'.- $w$, invert $a(v)$ open and shape with penknife $n$, or set different $n .-k$, substitute $h v$.

Tagged Letters $t, n, n, h, q$.

Use a turned spiritus lenis, or set inverted apostrophe. $-q$, differentiate tag somewhat, if desired.

\section{Optional Letters $\check{s}, \check{s}, i, u$.}

Presumably, $\check{s}$ is on hand. For $\check{s}$, $\check{s}$, if needed in purely scientific articles, set tag and cedilla beneath $\check{s}$.For $i, u$, if likewise needed, shave off and set close beneath. 


\title{
Appendix III.
}

\author{
Substitute Alphabet. ${ }^{1}$ \\ For popular articles. \\ (Modelled after Justi.)
}

A. Vowels.

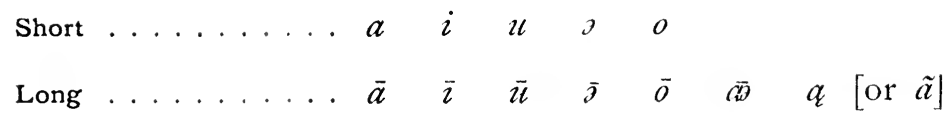

B. Consonants.

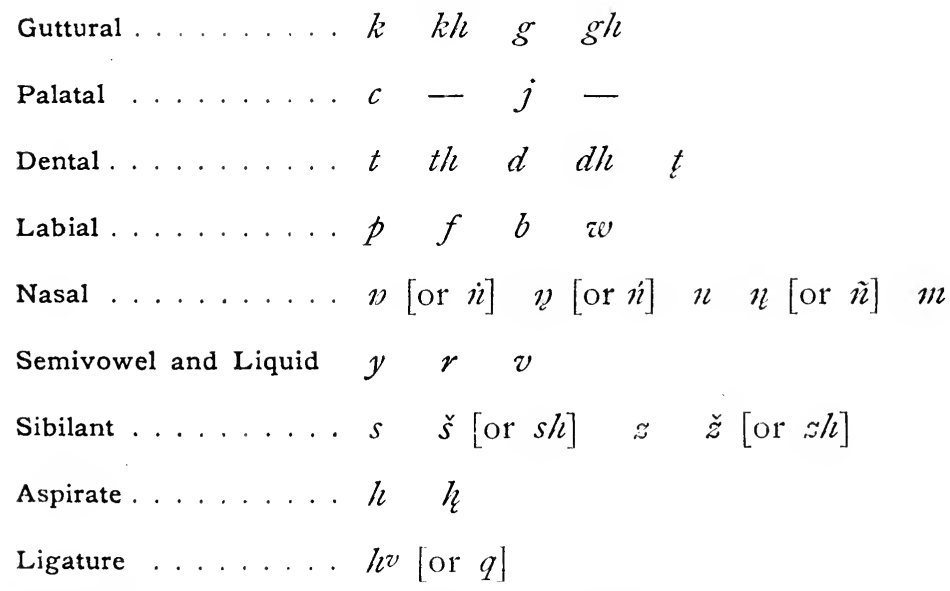

1 For suggestions to the Printer see Appendix II. 


\section{Appendix IV.}

Some of the different Systems of Transcription.

(References to the following Works - see Bibliography below.)

Anquetil du Perron-Zend Avesta (1771)-.Vol. ii. p. 424. Rask-Alter u. Echtheit d. Zendsprache, uibersetz. Hagen ( 1826$)$ pp. 46, 8 I .

Burnouf-Le Yaçna (I 833) p. xxxvii seq.

SPIEgeL-(Works) e. g. Av. ïbers. (1852-63); Commentar (1864-8); Vergl. Gram. (1882).

Haug-Gathas (I 858-60); Essays (1862-84); Zd. Pahl. Gloss. (I 867).

Lepsius - Das urspriingliche Zendalphabet (1862). Justi-Handbuch der Zendsprache (1864).

Rотн-(Contributions) e. g. Kalender (Z.D.M.G. xxiv); Beiträge (Z.D.M.G. xxv); Yaçna $3 I$ (I 876).

Fr. Müller-Zendstudien iv (Wien. Ac. Mai I 877); Beiträge u. Mittheilungen (Wiener Zeitschrift I 887 seq.).

Hübschmans-Iran. Studien (K.Z. xxiv. p. 370.-1877-9); Umschreibung (1 882).

PIscheL-Umschreibung (B.B. vi. p. 272.-I88I); Recension (Gött. gel. Anz. I 882 p. 737).

DE Harlez-Manuel de la langue de l'Avesta (1882). Sacred Books of the East-Translit. of Oriental Alph. Geldner-Metrik (1 877); Studien (1 882); Drei I'asht (1 884); (later contributions) in K.Z. and B.B.

Bartholomae-I'erbum (i 878); Gathas (i 879); Ar. Forsch. i. (1882); Handbuch (1883); A. F. ii-iii. (I886-7), and (later contributions) in K.Z. and B.B.

Brugmann-Grundriss der vergl. Gram. (I886-English transl. I 888). 
Systems of

(Parentheses denote forms

\begin{tabular}{c|ll|ll|ll|l|l|l|ll|ll|l|l}
\hline $\begin{array}{c}\text { Proposed } \\
\text { Transcription }\end{array}$ & $a$ & $\bar{a}$ & $i$ & $\bar{\imath}$ & $u$ & $\bar{u}$ & $\ddots$ & $\bar{j}$ & $e$ & $\bar{e}$ & 0 & $\bar{o}$ & $\bar{a}$ & $\alpha$ \\
\hline
\end{tabular}

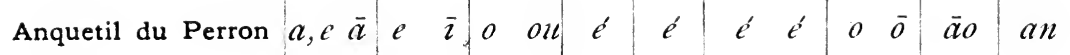

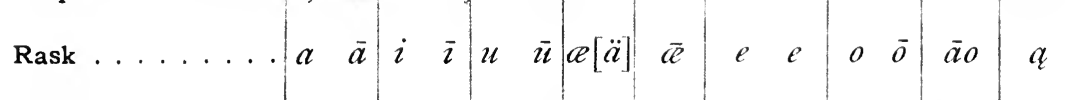

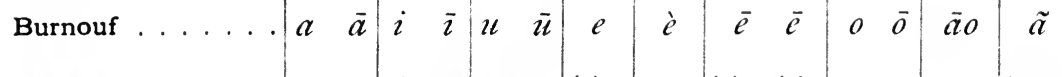

Spiege1......... $a$\begin{tabular}{ll|ll|ll|l|l|l|l|l|l|l} 
& $\bar{a}$ & $\bar{\imath}$ & $u$ & $\bar{u}$ & $(\bar{e}) e$ & $e^{\prime}$ & $(\bar{e}) e(\bar{e}) e$ & $o$ & $\bar{o}$ & $\bar{a} o$ & $(a \hat{n}) \tilde{a}$
\end{tabular}

\begin{tabular}{|c|cc|cc|cc|c|c|cc|cc|c|c|} 
Haug ........... & $a$ & $\bar{a}$ & $i$ & $\bar{\imath}$ & $u$ & $\bar{u}$ & $e$ & $\hat{c}$ & $\bar{e}$ & $\bar{e}$ & $o$ & $\bar{o}$ & $\bar{a} o$ & $\tilde{a}$
\end{tabular}

\begin{tabular}{ll|ll|ll|ll|l|l|ll|ll|l|l} 
Lepsius &... & $a$ & $\bar{a}$ & $i$ & $\bar{\imath}$ & $u$ & $\bar{u}$ & $e$ & $\bar{e}$ & $e$ & $\bar{e}$ & $o$ & $\bar{o}$ & $\dot{a}$ & $\tilde{a}$
\end{tabular}

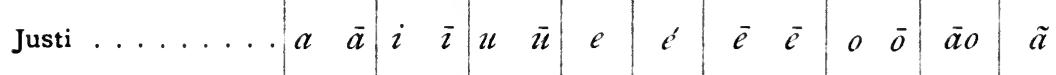

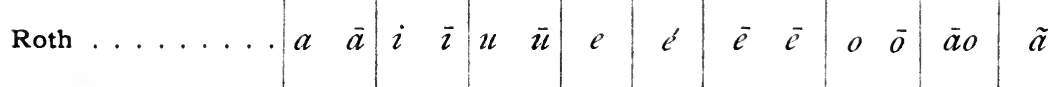

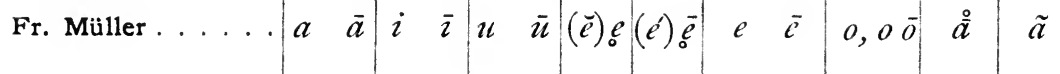

Hübschmann .... $a$\begin{tabular}{ll|ll|ll|l|l|ll|ll|l|l}
$a$ & $\bar{a}$ & $i$ & $\bar{\imath}$ & $u$ & $\bar{u}$ & $e$ & $\bar{e}$ & $e$ & $\bar{e}$ & $o$ & $\bar{o}$ & $\bar{a}$ & $(\tilde{a}) q$
\end{tabular}

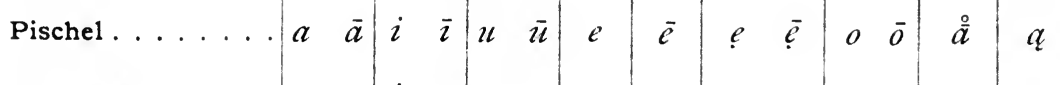

\begin{tabular}{ll|ll|ll|ll|l|l|ll|ll|l|l} 
de Harlez &... & $a$ & $\bar{a}$ & $i$ & $\bar{\imath}$ & $u$ & $\bar{u}$ & $e$ & $e^{\prime}$ & $\grave{e}$ & $\bar{e}$ & $o$ & $\bar{o}$ & $\bar{\alpha}$ & $\tilde{a}$
\end{tabular}

\begin{tabular}{|l|ll|ll|ll|l|l|ll|ll|l|l} 
Sacred Books.... & a & $\bar{a}$ & $\mathrm{i}$ & $\mathrm{i}$ & $\mathrm{u}$ & $\overline{\mathrm{u}}$ & $\mathrm{e}$ & $e$ & $\overline{\mathrm{e}}$ & $\overline{\mathrm{e}}$ & $\mathrm{o}$ & $\overline{\mathrm{o}}$ & $\alpha \mathrm{u}$ & $\mathrm{a}$
\end{tabular}

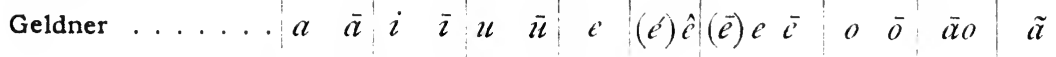

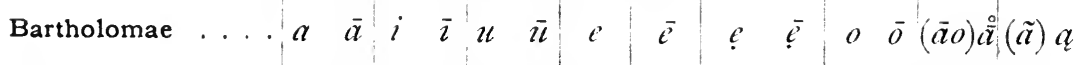

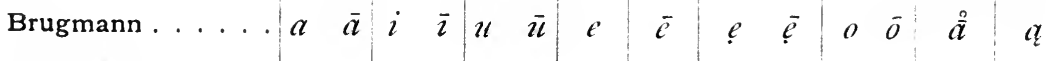

Proposed

$\begin{array}{llllllllllllllllll}\text { Transcription } & a & \bar{u} & i & \bar{\imath} & u & \bar{u} & \ddots & \bar{j} & \boldsymbol{e} & \overline{\mathcal{E}} & o & \bar{o} & a \bar{y} & a\end{array}$ 


\section{Transcription.}

temporarily used by an Author.)

\begin{tabular}{|c|c|c|c|c|c|c|c|c|c|c|}
\hline 9 & $b$ & c & q & $r$ & $\zeta$ & 10 & 6 & 9 & $G$ & $\varphi$ \\
\hline$k$ & $\eta$ & $g$ & $j$ & $c$ & $j$ & $t$ & $p$ & $d$ & $d$ & $t$ \\
\hline
\end{tabular}

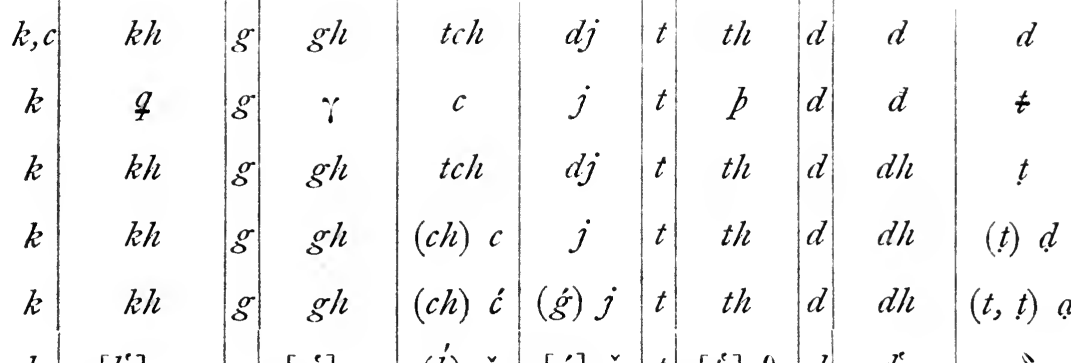

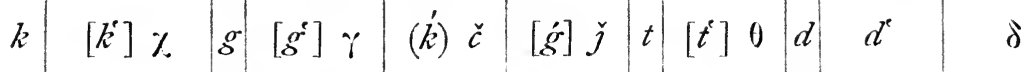

\begin{tabular}{l|l|ll|l|l|l|l|l|l|l}
$k$ & $k h$ & $g$ & $g h$ & $c$ & $j$ & $t$ & $t h$ & $d$ & $d h$ & $t$
\end{tabular}

\begin{tabular}{l|l|l|l|l|l|l|l|l|l|l}
$k$ & $k h$ & $g$ & $g h$ & $c$ & $g$ & $t$ & $t h$ & $d$ & $d h$ & $(t, t) t$
\end{tabular}

\begin{tabular}{ll|l|l|l|l|l|l|l|l|l}
$k$ & $\%$ & $g$ & $\ddots$ & $i$ & $g$ & $t$ & $\theta$ & $d$ & $\delta$ & $t$
\end{tabular}

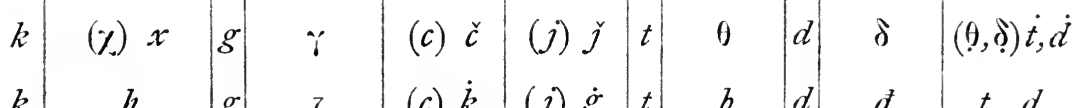

\begin{tabular}{c|c|c|c|c|c|c|c|c|c|c}
$k$ & $\eta$ & $g$ & $j$ & $(c) \dot{k}$ & $(j) \dot{g}$ & $t$ & $p$ & $d$ & $d$ & $\underline{t}, \underline{d}$ \\
$k$ & $\dot{k}$ & $g$ & $\dot{g}$ & $c$ & $j$ & $t$ & $t^{\prime}$ & $d$ & $d^{\prime}$ &
\end{tabular}

\begin{tabular}{ll|l|l|l|l|l|l|l|l|l}
$k$ & $k$ & $g$ & $g^{\prime}$ & $c$ & $j$ & $t$ & $t^{\prime}$ & $d$ & $d^{\prime}$ & $t$
\end{tabular}

\begin{tabular}{ll|l|l|l|l|l|l|l|l}
$\mathrm{k}$ & $\mathrm{kh}$ & $\mathrm{g}$ & $\mathrm{gh}$ & $k$ & $g$ & $\mathrm{t}$ & th & $\mathrm{d}$ & $\mathrm{dh}$
\end{tabular}

\begin{tabular}{ll|l|l|l|l|l|l|l|l|l}
$k$ & $k h$ & $g$ & $g h$ & $c$ & $(g) j$ & $t$ & $t h$ & $d$ & $d h$ & $(t) t$
\end{tabular}

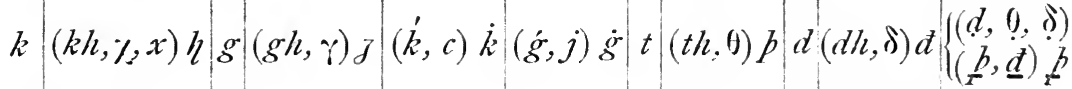

\begin{tabular}{l|l|l|l|l|l|l|l|l|l|l}
$k$ & $x$ & $g$ & $\ddots$ & $c$ & $j$ & $t$ & $b$ & $d$ & $d$ & $\underline{L}, \underline{d}$ \\
$k$ & $\eta$ & $g$ & $j$ & $c$ & $j$ & $t$ & $p$ & $d$ & $d$ & $t$
\end{tabular} 
Systems of (Parentheses denote forms

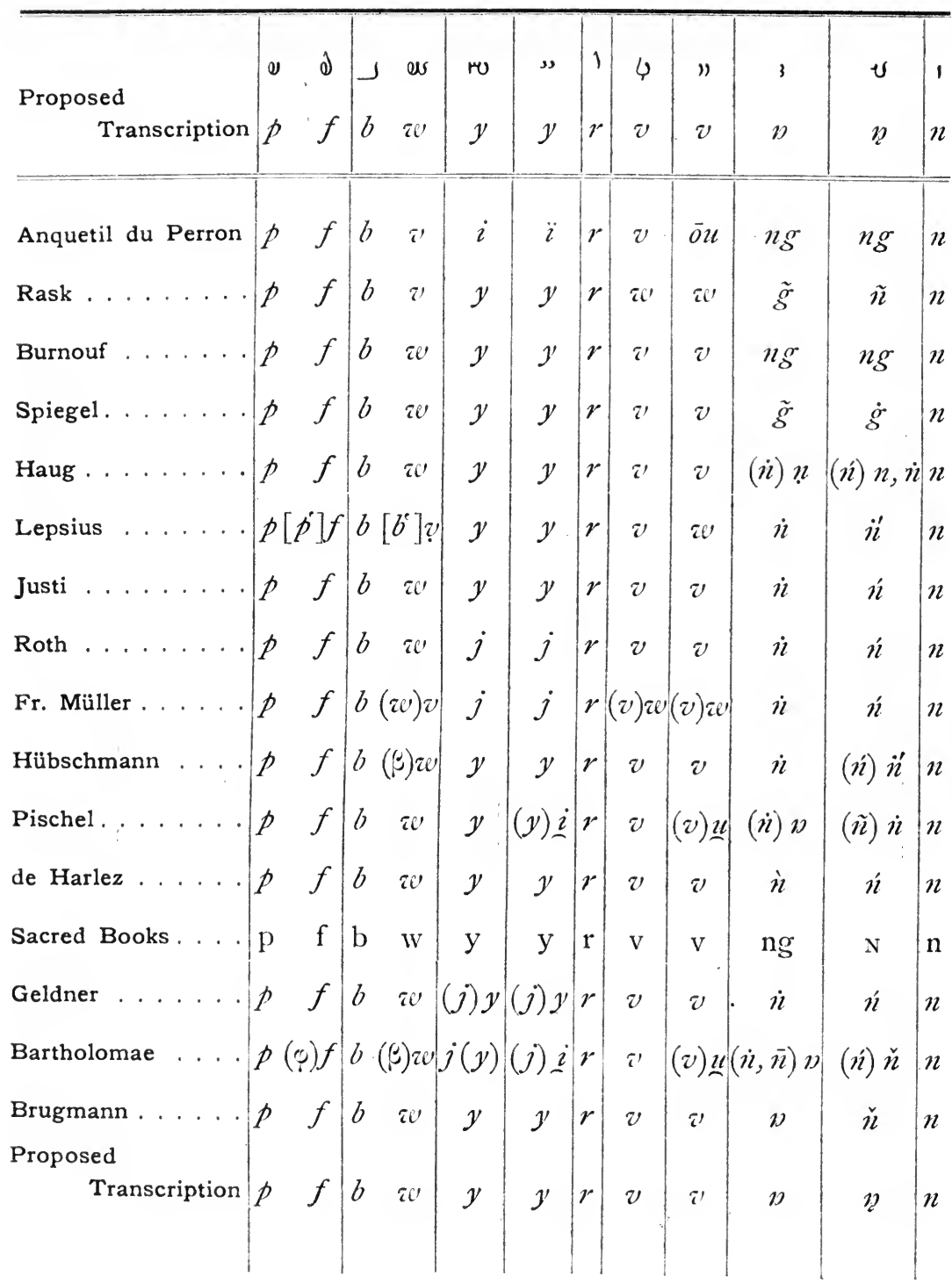




\section{Transcription.}

temporarily used by an Author.)

\begin{tabular}{|c|c|c|c|c|c|c|c|c|c|c|c|}
\hline ש世 & 6 & v & 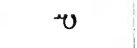 & ש & r & J & $\omega$ & r & $\omega$ & $\mu$ & th \\
\hline$\eta$ & $m$ & $s$ & $\check{s}$ & $(\check{s}) \check{s}$ & $(\check{s}) \check{s}$ & $s$ & $\check{z}$ & $h$ & $h$ & $h$ & $m$ \\
\hline $\bar{a} n$ & $m$ & $s$ & sch & sch & $s c h$ & $z$ & $j$ & $h$ & $k / l$ & $k / l$ & $\mathrm{hm}$ \\
\hline$N$ & $m$ & $f$ & $s$ & $s^{\prime}$ & $s k$ & $z$ & $\dot{s}$ & $\mathfrak{h}$ & $x$ & $x$ & $M I$ \\
\hline$i$ & $m$ & f & $s$ & $c h$ & $s k$ & $z$ & $j$ & $h$ & $q$ & $q$ & lom \\
\hline$i$ & $m$ & $(\xi) s$ & $(s) s h$ & $(s / l) s^{\prime}$ & $(s k) s h k$ & $z$ & $(\dot{j}) s h$ & $h$ & $q$ & $q, h v$ & $l m$ \\
\hline$\grave{n}$ & $m$ & (c) $s$ & $(s) s h$ & $s h$ & $(s k) s h k$ & $\approx$ & $(z) \approx h$ & $h$ & $q$ & $q$ & - \\
\hline$[\tilde{\bar{a}}] \tilde{u}$ & $m$ & {$[\dot{s}] s^{\prime}$} & $s$ & $\check{s}$ & $s k[\check{s}]$ & {$[\check{z}] \tilde{z}$} & $z$ & $h$ & $i$ & $i$ & $i n$ \\
\hline$\tilde{u}$ & $m$ & $\mathcal{f}$ & $s$ & sh & $s k$ & $z$ & $z h$ & $h$ & $q$ & $q$ & - \\
\hline$\tilde{n}$ & $m$ & f & $s$ & $s / l$ & sk & $\approx$ & $s h$ & $h$ & $q$ & $q$ & - \\
\hline$\tilde{n}$ & $m$ & $s$ & $\check{s}$ & $\check{s} / \iota$ & $\check{s} k$ & $z$ & $\check{z}$ & $h$ & $q$ & $q$ & - \\
\hline$i$ & $m$ & $s$ & $\check{s}$ & $\check{S}$ & $(\check{s} k, \check{s}) \grave{s}$ & $z$ & $\ddot{z}$ & $h$ & (ll.) $x^{\prime}$ & $(h F) x a$ & $\operatorname{hm}(i n)$ \\
\hline$\breve{n}$ & $m$ & $s$ & $s$ & $\check{s}$ & - & $z$ & 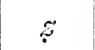 & $h$ & $h \cdot$ & $(h \cdot) \zeta$ & - \\
\hline$\tilde{n}$ & $m$ & $f s$ & $\dot{s}$ & $s h$ & $s k$ & $\approx$ & $s h$ & $h$ & $h v$ & $h^{v}$ & $h m$ \\
\hline$n$ & $\mathrm{~m}$ & S & $s$ & $\mathrm{sh}$ & $s \mathrm{k}$ & $Z$ & $z h$ & h & $l i{ }^{\prime}$ & $h v$ & - \\
\hline (n) $\tilde{u}$ & $m$ & (c) $s$ & $(s, \dot{s}, s h) \check{s}$ & $(s / l) \check{s}$ & $(s k, s h) \check{s}$ & $\approx$ & $(s / l) \check{z}$ & $h$ & (q) $! l$ & $q h v$ & - \\
\hline$(\tilde{n}, \breve{n}) n$ & $m$ & $s$ & $(\check{s}, s) \check{s}$ & $(s h, \breve{s}) \tilde{s}$ & $(\check{s} k, \check{s}, \dot{s}) \check{s}$ & $z$ & $(\check{z}, \ddot{z}) \check{z}$ & $h$ & $(q, h \cdot) h$ & $(q, h v) h$ & $m$ \\
\hline$n$ & $m$ & $s$ & $\dot{s}$ & $\check{s}$ & $\dot{s}$ & $\approx$ & $\check{z}$ & $h$ & $x^{\prime}$ & $x \pi$ & - \\
\hline$\eta$ & $m$ & $s$ & $\check{s}$ & $(\check{\tilde{s}}) \check{s}$ & $(\check{s}) \check{s}$ & $z$ & $\check{z}$ & $h$ & h & $h$ & $m$ \\
\hline
\end{tabular}




\section{Appendix V.}

\section{Partial Bibliography.}

Writings on the Arestan Alphabet and its Transcription.

Anquetil du Perron-Zend-Avesta, Ouvrage de Zoroastre, ii. p. 425.--Paris I $77 \mathrm{I}$.

R. RAsK-Ueber das Alter und Echtheit der Zend-Sprache, iibersetzt von F. H. v. d. Hagen, pp. 46-8I.-Berlin I 826 .

E. Burnouf-Commentaire sur le Y'aşna; L'Alphabet Zend, pp. xxxii-cliii.-Paris I 833 .

H. Brockhaus I'endidad Sade, p. xii. [Alphabet.]-Leipzig I 850 .

- in Zeitschrift der deutschen morgenländischen Gesellschaft, xvii. p. 539.

C. Arendi-Phonetische Bemerkungen (Kuhn's Beiträge ii. p. 429).-I $86 \mathrm{I}$.

M. HAUG-Essays on the Parsis (I ed. p. 52-57; 3 ed. West, p. x).-Bombay, London i 862 - I 884 .

- Zand-Pahlavi Glossary p. 8I. [Alphabet.]-Bombay, London i 867 .

LePsius-Das ursprïngliche Zendalphabet (in philolog. u. histor. Abhandlungen d. kgl. Ak. der Wissenschaften zu Berl. 31. März u. I 4. Juli I 862). - Berlin I 863 .

F. Justi-Handbuch der Zendsprache p.x seq.-Leipzig I 864. FR. SPIEGEL-Gramm. der altbaktr. Sprache.--Leipzig I 867.

- Vergleichende Gramm. der altéranischen Sprachen.Leipzig I 882.

- Zur Geschichte des Avesta Alphabets (Bezzenberger's Beiträge, ix. p. I73).-I 885 . 
KunN \& Schleicher-Umschreibung des altindischen und altbaktrischen Alphabets (Kuhn u. Schleicher's Beiträge z. vergl. Sprachforschung v. p. I44).-I 868.

Fr. MüLleR-Zendstudien iv: Ueber die Zischlaute des Altbacktrischen. (Sitzb. d. k. Akademie d. Wissensch. -Mai i877.)-Wien 1877.

H. Hübschmann-Iranische Studien i: Ueber den lautwerth des Zendalphabet.-Mit 3 Tafeln. (Kuhn's Zeitschrift xxiv. p. 323-427.)--Berlin $1878-9$.

- Die Umschreibung der iranischen Sprachen und des Armenischen.-Leipzig I 882.

C. Salemann-Ueber eine Parsenhandschrift der kaiserl. öfentl. Bibliothek zu St. Petersburg.-Leyden I 879. [Could not consult.]

C. DE HARLEZ-De l'Alphabet avestique et de sa Transcription.-Paris I880. [Could not consult.]

- De la Transcription de l'Alphabet avestique (Bezzenberger's Beiträge vii. pp. I27-139). - I 883 .

SACRED Books of the EAST-Transliteration of Oriental Alphabets (see end of each volume).-London I 880 seq.

R. PISCHEL-Die Umschreibung des Baktrischen (Bezzenberger's Beiträge iv. pp. 272-282). -Göttingen I $88 \mathrm{I}$.

- Recension von Bartholomae's 'Arischen Forschungen i' (Götting. gel. Anz. I4. Juni 1882 p. 737 seq.).

KIRSTE-Die constitutionellen I'erschiedenheiten der Verschlusslaute im Indogermanischen p. 7 seq.-Graz I 88 I. [Could not consult.]

K. F. Geldner-Metrik des jüngeren Avesta p. xir. |Mere mention.]-Tübingen I 877 .

- Studien zum Avesta i. p. 4. [Mere mention.]-Strassburg I 882.

- Miscellen aus dem Avesta. [On $\bar{e}, \dot{n}$.$] (Kuhn's Zeit-$ schrift xxvii. p. 257 seq.)-I 883.

- Drei Yasht aus dem Zendavesta pp. vi--xi. [On the sibilants.] -Stuttgart I 884 . 
Chr. BARThOlOMAe-Das altiranische Verbum p. ii. [Alphabet.]-München I 878 .

- Die Gäthās: Metrum, Text u. s. w. p. 3.-Halle i 879.

- Arische Forschungen i: Anhang pp. I55-i63.-Halle I 879 .

- Ar. Forsch. ii-iii Vorwort.-Halle is86-7.

- Beiträge zur altiranischen Grammatik i. [On sibilants and nasals.] (Bezzenberger's Beiträge vii. pp. I 88-195.) $-\mathrm{I} 883$.

- Handbuch der altiranischen Dialekte.-Leipzig 1883.

E. DILlon-Die Umschreibung der eranischen Sprachen pp. I-I6.-Leipzig I883.

D. Peshotan Sanjana-Civilization of the Eastern Iranians Vol. ii. pp. 273-286 (The Iranian Alphabets, transl. from Spiegel's Eranische Alterthumskunde iii. pp. 759-771).-London I 886.

P. DE LAGARDE-Mittheilungen ii. Bemerkungen iiber die Awesta-Schrift pp. 38-48.-Göttingen 1887.

K. Brugmann-Grundriss der vergleichenden Grammatik der indogerm. Sprachen Bd. i. p. vii, 25 ; Bd. ii. Vorwort pp. vii-viii.-Strassburg I886-i 889.-English translation $\mathrm{I} 888$. 



\section{RETURN CIRCULATION DEPARTMENT}

IO $\rightarrow 202$ Main Library

\begin{tabular}{l|l|l}
\hline $\begin{array}{l}\text { LOAN PERIOD } 1 \\
\text { HOME USE }\end{array}$ & 2 & 3 \\
\hline 4 & 5 & 6 \\
\hline
\end{tabular}

\section{ALL BOOKS MAY BE RECALLED AFTER 7 DAYS}

1. month loans may be renewed by calling 642.3405

6-month loans may be recharged by bringing books to Circulation Desk

Renewals and recharges may be made 4 days prior to due date

\section{DUE AS STAMPED BELOW}

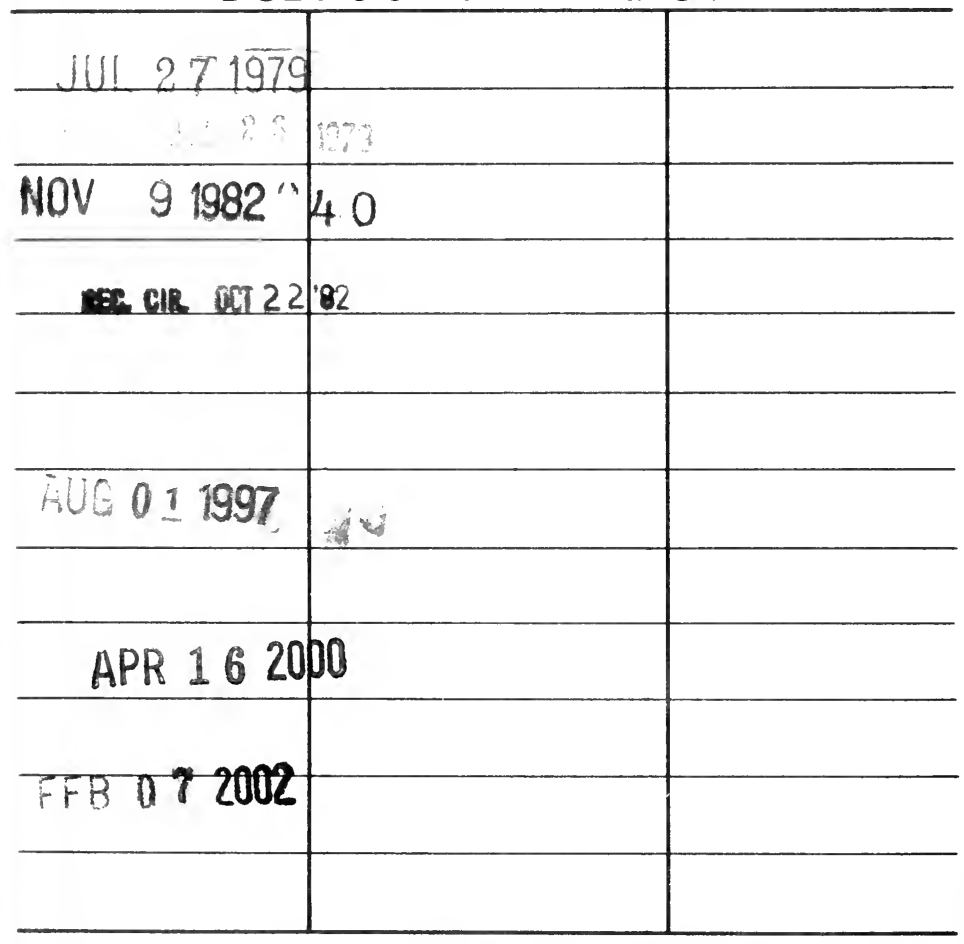

UNIVERSITY OF CALIFORNIA, BERKELEY

FORM NO. DD6, 60m, 11/78 BERKELEY, CA 94720 
U. C. BERKELEY LIBRARIES

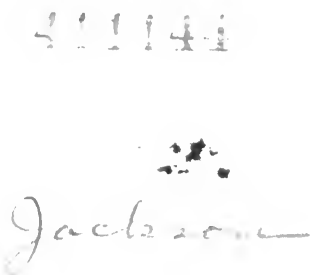

UNIVERSITY OF CALIFORNIA LIBRARY 
